\title{
Duque de Caxias: novos e velhos desafios em questão
}

André Luiz Teodoro Rodrigues

\section{(2) OpenEdition}

Journals

Edição electrónica

URL: http://journals.openedition.org/espacoeconomia/2717

DOI: $10.4000 /$ espacoeconomia.2717

ISSN: 2317-7837

\section{Editora}

Núcleo de Pesquisa Espaço \& Economia

Refêrencia eletrónica

André Luiz Teodoro Rodrigues, «Duque de Caxias: novos e velhos desafios em questão », Espaço e Economia [Online], 10 | 2017, posto online no dia 11 julho 2017, consultado o 19 abril 2019. URL http://journals.openedition.org/espacoeconomia/2717 ; DOI : 10.4000/espacoeconomia.2717

Este documento foi criado de forma automática no dia 19 Abril 2019.

(C) NUPEE 


\section{Duque de Caxias: novos e velhos desafios em questão}

André Luiz Teodoro Rodrigues

Capa

DUQUE DE CAXIAS

A GEOGRAFIA DE UM ESPAÇO DESIGUAL

André Tenreiro

Organizador

Cleonice Puggian

Manoel Ricardo Simōes

Marcelo Ramos do Santos

Sebastião Fernandes Raulino

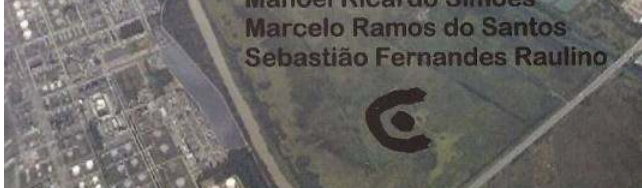

Foto da capa 


\section{TENREIRO, André (Org.). Duque de Caxias - A geografia de um espaço desigual. Nova Iguaçu, RJ: Entorno, 2015. 176 p.}

1 "Duque de Caxias - A geografia de um espaço desigual", livro organizado por André Terneiro, professor de geografia da rede municipal de Duque de Caxias e especialista em Sociologia Urbana, e com capítulos assinados por Cleonice Puggian, professora-adjunta da FFP-UERJ, Manoel Ricardo Simões, professor titular do IFRJ, Marcelo Ramos dos Santos, professor de Geografia da Secretaria Municipal de Educação de Duque de Caxias, e Sebastião Fernandes Raulino, doutor em planejamento urbano e regional e professor da Faculdade de Ciências e Letras de Duque de Caxias (FEUDUC), tem como objetivo estudar esta cidade tão importante da Região Metropolitana Fluminense, enumerando velhos e novos problemas, abordando desde transtornos ambientais até as mazelas sociais de uma das cidades economicamente mais ricas do Brasil.

2 As vicissitudes existentes nessa cidade, situada na Baixada Fluminense, nas margens da Baía de Guanabara, são extremamente evidentes ${ }^{1}$. Já no título da obra, que alude a um "espaço desigual", já remete a esta dicotomia, fazendo com o livro seja assim pensado e dividido. Em primeiro capítulo, intitulado "Dentro de um espaço desigual" e de autoria de André Tenreiro, aborda a desproporcionalidade socioeconômica da cidade, com aéreas de grande suporte em infraestrutura e ambientes de insalubridade e com dilemas de afirmação identitária. No segundo e terceiro capítulos, de autoria de Manoel Ricardo Simões e intitulados respectivamente "Pequeno histórico da ocupação de Duque de Caxias" e "Duque de Caxias no contexto regional metropolitano e da Baixada Fluminense", por meio da história regional e da ocupação da cidade do Rio de Janeiro, visa entender como se deu esse espraiamento urbano até o município de Duque de Caxias, revelando a importância desta cidade para o contexto regional metropolitano e de protagonismo na Baixada Fluminense. No quarto capítulo, "Duque de Caxias: Um estudo da economia local", de Marcelo Ramos dos Santos, economia é a palavra-chave, pois Caxias deixa de ter característica unicamente de cidade-dormitório e passa a ter uma economia própria e ainda consegue polarizar municípios ao seu entorno, transformando-se em um centro regional.

O quinto capítulo - "Um ambiente de injustiças", de Cleonice Puggian e Sebastião Fernandes Raulino - se concentra na reflexão acerca das injustiças ambientais e sociais e demonstra como historicamente essa região se tornou uma zona de sacrifício para o desenvolvimento da até então capital federal, Rio de Janeiro. Com a própria industrialização e urbanização do território de Duque de Caxias, a vinda da Fábrica Nacional de Motores (FNM), as instalações da Refinaria de Duque de Caxias (REDUC) e da Fábrica de Borracha Sintética (FABOR) - as duas últimas construídas às margens da Baía de Guanabara - e a atividade do Aterro Sanitário de Jardim Gramacho (o maior aterro sanitário da América Latina!) ${ }^{2}$ comprovam que o progresso e o desenvolvimento estão acima da preservação e uso sustentável. Fechando o livro, o sexto capítulo, também de autoria de André Tenreiro e intitulado "O trânsito parou. Qual é o plano?", se concentra nos entraves e desafios da Cidade de Duque de Caxias no que diz respeito a mobilidade urbana, mediante as obras do plano diretor urbanístico (PDU) em grande parte paradas e inacabadas, a ausência de infraestrutura, o monopólio de empresas de ônibus no município, além da tarifa diferenciada para cada distrito de Caxias, que corrobora para um transporte caro e de péssima qualidade. 
4 Mediante este quadro analítico, é possível destacar alguns dos principais debates presentes na obra.

\section{I - A busca de uma compreensão histórica e a fuga do estigma pré- emancipação}

5 A ocupação do município de Duque de Caxias se confunde com o histórico de ocupação da até então capital federal, o Rio de Janeiro. Toda esta região ficou sob a tutela administrativa do Rio de Janeiro até 1833, e somente após este ano foi para a então criada Vila de Iguaçu. Esse território anteriormente já havia sido ocupado por povos préhistóricos coletadores há 15 mil anos, com a evidência dos sambaquis tupi-guaranis, parcialmente destruídos pela ação antrópica. A partir do século XVI, com a colonização portuguesa e a administração territorial por meio das sesmarias, Cristóvão Monteiro obteve o direito de utilizá-la de sua maneira, às margens do Rio Iguaçu. Todavia, esta demarcação ganhou realmente importância no ciclo do ouro, no século XVII, onde a Igreja Nossa Senhora do Pilar, construção de 1612, tornou-se um entreposto para descanso, rituais religiosos, posto comercial, formando naquela região um dos primeiros núcleos urbanos da região. Os rios eram bastante úteis para transporte de mercadorias, principalmente para o ouro oriundo de Minas Gerais, e os portos fluviais da Baixada ganharam grande importância, pois os mesmos englobavam atividades econômicas e o transporte de pessoas.

6 Com a chegada da família real na cidade do Rio de Janeiro, então capital do Império, houve um significativo aumento da população e, consequentemente, o fluxo de atividades econômicas também teve um incremento, aumentando a importância dos portos da Baixada. Todavia, com os sucessivos desmatamentos, ausência de limpeza e assoreamentos dos brejos, os rios se tornaram menos eficientes causando prejuízos a todos os usuários, provocando um breve esvaziamento desta região com a infestação de doenças e epidemias locais. Este panorama começa a mudar a partir da construção da Estrada de Ferro Leopoldina ou Rio de Janeiro Northern Railway, em 1886, que cruzava o até então território de Iguaçu, realizando uma integração com a capital federal, concomitante aos esforços de políticas de saneamento na Baixada, em 1910, para acabar com a propagação de epidemia em áreas pantanosas.

7 As condições de vida melhoraram com a progressiva modernização local. Isto teve origem com o novo traçado da rodovia Rio-Petrópolis que permitiu a atração de novos moradores, mas o estigma da herança negativa da até então Merity ainda incomodava. A "Merity do Pavor" era passado, fato esse que foi de expressivo valor para os moradores, os quais em 1930 trocaram a placa da estação de trem de Merity para Caxias, em homenagem a Duque de Caxias, que tinha nascido na Fazenda Taquara, futura Duque de Caxias. Em 1931, Duque de Caxias tornou-se o oitavo distrito de Nova Iguaçu, após diversas tentativas por meio do Interventor Plínio Casado, e então os loteamentos foram ocupados, o distrito foi crescendo populacionalmente e as lideranças locais formaram a União Popular Caxiense. Tais lideranças almejavam se separar de Nova Iguaçu a qualquer custo, já que não se viam representados pelo mesmo. No dia 31 de Dezembro de 1943, o Interventor Estadual Amaral Peixoto eleva o distrito a município, emancipando-se de Nova Iguaçu. A instalação da Fábrica Nacional de Motores (FNM), em 1940, corroborou com uma das justificativas para emancipação de Duque de Caxias, pois já nascia como símbolo de em um modelo de desenvolvimento e progresso, idealização nacional de um emergente Brasil 
"moderno-industrial". Com a construção da Avenida Brasil em 1946 e a implantação da Refinaria de Duque de Caxias, nas margens da Rodovia Washington Luís, em 1961, e a implementação da Fábrica de Borracha Sintética (FABOR) em 1962, proporcionaram a Duque de Caxias a tentativa de fuga de um passado negativo e na busca de um progresso a partir do processo de industrialização que o município estava enfrentando.

\section{II - Uma cidade de ambiente com profundas adversidades socioambientais}

8 O território de Duque de Caxias apresenta diversas particularidades, desde áreas com dificuldades de afirmação identitária até desmatamento descarado de áreas de preservação ambiental em detrimento de atividades econômicas. Esse ambiente é dividido em quatro distritos: Duque de Caxias ( $1^{\circ}$ distrito), Campos Elíseos ( $2^{\circ}$ distrito), Imbariê ( $3^{\circ}$ distrito) e Xerém ( $4^{\circ}$ distrito), onde o grau de desenvolvimento de cada um deles vária de acordo com a distância com a matriz distrital. Os distritos mais populosos e desenvolvidos são de Duque de Caxias e Campos Elíseos, já as terras longínquas de Xerém e Imbariê caracterizam-se por uma infraestrutura mais simples e de ausência de diálogo com o distrito-sede. Isto foi um dos motivos da mudança da sede da prefeitura municipal de Duque de Caxias para o centro geográfico do município, em Jardim Primavera ( $2^{\circ}$ distrito), por conta de tensões emancipatórias dos dois últimos distritos e pela tentativa de integração com todos os distritos. Trata-se de um espaço desigual, pois mesmo tendo uma das maiores arrecadações de ICMS e Produto Interno Bruto do Estado do Rio de Janeiro, Duque de Caxias continua tendo baixos Índices de Desenvolvimento Humano, onde a diferença nos valores imobiliários é exorbitante - os imóveis mais valiosos possuem facilidades logísticas pela proximidade de hospitais, lojas, bancos, infraestrutura urbana e escolas mais qualificadas, enquanto áreas nas comunidades fronteiriças ao Rio Sarapuí não possuem nenhum tipo de infraestrutura, com habitações em condições extremamente insalubres, sem qualquer saneamento básico e convívio constante com o descaso das autoridades públicas. Tal realidade se estende a comunidades vizinhas ao Aterro Sanitário do Jardim Gramacho, que vivem, mesmo depois da sua desativação, em situação degradante, sem asfalto, saneamento básico e com moradias feitas de madeira. Por este motivo, uma característica muito utilizada pela população mais humilde, moradora de áreas periféricas, é a "autoconstrução", onde o morador, com o auxílio de familiares e amigos, constrói por conta própria não somente a casa, mas também uma boa parte dos equipamentos coletivos do bairro.

9 As mazelas sociais corroboram ainda mais para o espraiamento das injustiças ambientais, pois se trata de um município onde o desenvolvimento se sobrepõe à necessidade de preservar ou cuidar da natureza, e que desde sua emancipação se preocupa pouco com a temática de conservação; isto se reflete no assoreamento das bacias fluviais que serviam de portos antes mesmo de se tornar município até a emissão de poluentes através do Complexo Petroquímico de Duque de Caxias. O "progresso" apareceu primeiramente com a "Cidade dos Motores" - oriunda da instalação da Fábrica Nacional de Motores, implementada numa área 54 milhões de metros quadrados - atualmente situada na reserva biológica de Tinguá; a seguir, a construção da Rodovia Rio-Petrópolis desmatou milhares de árvores originais de Mata Atlântica, bem como a implantação da Refinaria de Duque de Caxias, na margem da Baía de Guanabara, aumentou a poluição da bacia hidrográfica onde está situada, devido ao despejo de resíduos e vazamentos de petróleo - 
uma vez que seus efluentes líquidos contêm grandes quantidades de óleos e graxas, metais pesados, inclusive cádmio e mercúrio, fenóis e carga orgânica - ocasionaram grandes problemas ambientais. Os manguezais existentes foram diretamente impactados pela poluição da refinaria, os quais se localizam no litoral de Duque de Caxias. Além disso, bairros próximos à refinaria, como Campos Elíseos, Jardim Primavera, Saracuruna e São Bento sofrem impactos diretos da emissão de poluentes na atmosfera, provocando na população do entorno enfermidades respiratórias e dermatológicas, desvalorização do território, poluição dos lençóis freáticos, ar e do solo.

10 Há também problemas bem antigos e menos visíveis, como: [1] a remoção de saibro, extremamente prejudicial ao meio ambiente, pois retira a cobertura vegetal do solo deixando o mesmo vulnerável a processos erosivos, podendo causar deslizamentos, doenças respiratórias e após o esgotamento da reserva mineral, o local pode ser disputado por grileiros; [2] o aterramento de áreas de várzeas, por conta de atividades econômicas ocasionando como consequências inundações, assoreamento de rios e enchentes na cidade; [3] a construção do Arco Metropolitano, que impacta a Reserva biológica do Tinguá (Nova Iguaçu, Japeri, Duque de Caxias, Belford Roxo, Queimados e outros), o Parque Municipal de Nova Iguaçu (Nova Iguaçu e Mesquita) e a APA (Área de Proteção Ambiental) de Guapimirim (Itaboraí, Guapimirim, São Gonçalo e Magé); além disso, a poluição atmosférica e sonora é uma realidade presente nesse ambiente rodoviário, pois o Arco corta a Floreta Nacional Mário Xavier, ambiente de grande biodiversidade de fauna e flora; [4] exposição da região conhecida como Cidade dos Meninos à contaminação por 40 toneladas de Hexaclorohexano ( $\mathrm{HCH})$, popularmente conhecido como "pó-de-broca", utilizado como pesticida. Este lugar, onde funcionava o antigo internato Fundação Abrigo Cristo Redentor para rapazes, devido à grande quantidade de casos de malária no segundo quartel do século XX, foi utilizada pelo Ministério de Educação e Saúde para construção de pavilhões do Instituto de Malariologia e posteriormente, a Fábrica de Produtos Profiláticos, onde eram produzidos: Hexaclorociclohexano $(\mathrm{HCH})$, Arsenito de Cobre, Hexaclorobenzeno (BHC), Monofluoroaetato de Sódio, Cianeto de Cálcio e Diclorodifenil tricloretano (DDT). Mesmo fechada em 1961, a fábrica deixou na antiga instalação cerca de 400 toneladas de compostos tóxicos já explicitados, sem qualquer tipo de proteção, o que levou a contaminação do solo, da água e da população que vivia ao entorno; [5] por fim, a mineração de areia também está vigente na configuração econômica e ambiental do município, no bairro do Amapá, $4 .^{\circ}$ distrito de Caxias, causando muitos danos ao meio ambiente, com a contaminação dos lençóis, desmatamento e extinção da fauna e flora local.

De positivo, Duque de Caxias tem ampliado o número de unidades de conservação , com relevantes remanescentes da mata atlântica, aglutinando com o Mosaico da Mata Atlântica Central Fluminense (MCF). Nessa cidade, há quatro unidades de proteção integral e três unidades de uso sustentável, sendo quatro municipais, uma estadual e duas federais: a Área de Proteção Ambiental do São Bento, Área de Proteção Ambiental do Alto Iguaçu, Área de Proteção Ambiental de Petrópolis, Parque Natural Municipal da Taquara, Parque Natural Municipal da Caixa d'Água, Reserva Biológica do Parque Equitativa e Reserva Biológica do Tinguá. Todavia, constantes ataques a esses ambientes naturais têm sido realizadas, por especulação imobiliária, exploração de recursos minerais próximos e queimadas criminosas com o intuito de aumentar a incerteza das demarcações vigentes das APA's. 


\section{III - A mobilidade urbana do município de Duque de Caxias}

12 Com uma população em 2010 de 855.048 habitantes, em um território de $466,8 \mathrm{Km}^{2}$, a cidade de Duque de Caxias é a terceira mais populosa do Estado, atrás apenas de São Gonçalo e o Rio de Janeiro, representando cerca de 5\% da população total do Estado. Com esses números, um problema de relevo é a mobilidade urbana. Caxias conta com a antiga Estrada de Ferro Leopoldina, com dois ramais ferroviários, ramal Saracuruna e Vila Inhomirim, contabilizando 10 estações de trem sob a administração da Supervia: Duque de Caxias, Corte 8, Gramacho, Campos Elíseos, Jardim Primavera e Saracuruna, no Ramal Saracuruna, e Morambi, Imbariê, Santa Lúcia e Parada Angélica, no Ramal Vila Inhomirim, que termina em Magé. A ocupação de Duque de Caxias se deu de forma mais dinâmica por meio da instalação desta linha férrea, tendo um crescimento populacional vertiginoso após a construção do novo traçado da Rodovia Rio-Petrópolis (BR-040). Duque de Caxias tem características históricas de cidade-dormitório, cujo advento da industrialização e urbanização impactaram na suavização desta característica, mas não em seu ocaso. Grandes fluxos de pessoas saem direção à capital fluminense por meio da Rodovia Washington Luís (BR-040), que tem acesso direto para a Avenida Brasil - um dos principais logradouros da cidade do Rio de Janeiro - e para a Linha Vermelha (RJ-071) por modais rodoviários, como carro, ônibus e vans; pelo modal ferroviário, os trens da Surpervia transportam cerca de 10 mil pessoas por dia.

Em consequência aos grandes fluxos de automóveis em direção a cidade do Rio de Janeiro e ao primeiro distrito de Duque de Caxias, engarrafamentos e lentidões são frequentes durante a semana, principalmente em horários de pico, no começo da Rodovia Washington Luís. Acreditava-se que com o término da construção do Arco Metropolitano do Rio de Janeiro, o trânsito em Duque de Caxias melhoraria, pois pensava-se que os caminhões de cargas que faziam trajetos Norte-sul passariam direto por está autoestrada, mas é isso que de fato está ocorrendo. Mesmo vizinho do município mais importante do Estado, próximo ao Aeroporto Internacional Antônio Carlos Jobim (Galeão) e da Rodovia Presidente Dutra (BR-116) e da Avenida Brasil, Duque de Caxias sofre com a própria ineficiência da infraestrutura municipal, e, em nossa opinião, com a ausência de um planejamento regional efetivo na esfera metropolitana.

A esperança reside, por exemplo, na efetivação do Plano Diretor Urbanístico (PDU) e na reengenharia de trânsito com o intuito de melhorar o tráfego nas imediações e centro de Duque de Caxias. Da mesma maneira, tanto o desenvolvimento de um modal hidroviário no litoral de Duque de Caxias, ligando a cidade ao Rio de Janeiro, São Gonçalo, Niterói, Ilha do Governador etc., diminuiria o fluxo de veículos automotores em direção ao centro e municípios da região metropolitana, quanto os projetos de BRT (Bus Rapid Transit), com a junção de ciclovias ao seu entorno, até o bairro de Santa Cruz da Serra na Rodovia Washington Luís (BR-040), a construção da Transbaixada I e II, interligando alguns municípios da Baixada Fluminense e a construção da Ciclovia Ilha-Caxias, com 17 trechos para servir de um transporte alternativo seriam propostas bastante interessantes de escoamento do trânsito. 


\section{IV - Os arranjos econômicos de Duque de Caxias e sua posição no contexto regional}

Uma das cidades mais populosas do Brasil e que está entre as 30 mais ricas, Duque de Caxias tem um perfil bem diferente das demais cidades da região metropolitana e do Estado do Rio de Janeiro. Essa cidade ficou estigmatizada como cidade-dormitório, reduto de trabalhadores de baixa renda e migrantes que não moravam na até então capital federal, Rio de Janeiro, por conta do alto preço do solo e de moradias. Operários e trabalhadores realizavam com intensidade a migração pendular, saindo de manhã cedo e voltando ao final da tarde em transportes públicos. Todavia, a Rodovia Washington Luís (BR-040), a Refinaria de Duque de Caxias (REDUC), Fábrica Nacional de Motores (FNM), a Estrada de Ferro Leopoldina, a Fábrica de Borracha Sintética (FABOR) garantiram à cidade uma nova feição, promovendo importante protagonismo na economia metropolitana.

Se no setor da agropecuária, a parcela de participação é pequena, restringindo-se apenas ao distrito de Xerém, com uma pequena criação "extensiva" de gado bovino que representa $0,05 \%$ na participação do PIB, o setor que apresenta maior destaque é o de serviços e comércio, responsável pela maior participação no somatório das riquezas produzidas no município, os quais se concentram nos dois primeiros distritos de Duque de Caxias. Grande parte desse crescimento do comércio, intermediação financeira, atividades imobiliárias e aluguéis, transportes e logística vem do atributo de tal município situar-se a $17 \mathrm{~km}$ da capital do Estado e do grande número de cidades vizinhas de importância no contexto metropolitano, como Magé, Nova Iguaçu, São João de Meriti, Petrópolis e Belford Roxo.

17 O setor industrial de Duque de Caxias é de enorme importância para a economia da cidade, implicando na formação deste município desde a instalação da Fábrica Nacional de Motores (FNM), em Xerém, presente até no brasão da cidade, até a Refinaria de Duque de Caxias (REDUC). A Refinaria de Duque de Caxias, responsável pelo surto industrial da cidade nas décadas de 1970 e 1980, continua sendo um das principais peças da economia caxiense, dada a sua relevância econômica e social. A ampliação do número de empregados na REDUC, chegando a 10.960 empregados, mesmo que menos da metade efetivos, revela a consolidação da cidade entre as cinco maiores no valor adicionado bruto da indústria do estado do Rio de Janeiro. o bairro de Campos Elíseos, nas margens da Rodovia Washington Luiz, tornou-se um importante complexo industrial com base nos setores petrolífero e químico e um forte eixo econômico da região metropolitana e do estado. Aliás, na mesma região emergiu o polo moveleiro, que apresenta uma grande variedade de móveis de excelente qualidade e considerável tradição no panorama regional, bem como o setor de vestuário, com vendas crescentes.

O livro que resenhamos é um material bastante abrangente da cidade de Duque de Caxias, ilustrando com qualidade os avanços econômicos da cidade e seu protagonismo na região metropolitana, que não se reflete nos aspectos sociais da cidade. Prova disso é que se trata de município com um dos maiores PIB per capita do Estado, aproximadamente R\$ 30.000,00, mas que está em 49. lugar no Índice Desenvolvimento Humano Municipal, entre 92 municípios. 0 território caxiense é sem sombra de dúvidas um espaço desigual, onde em certas áreas há um ambiente socioeconômico extremamente desenvolvido, com infraestrutura que corrobora para tal afirmação, como o bairro Jardim 25 de Agosto; todavia, em contraposição, bairros como Jardim Gramacho, Santa Lúcia, Parque das 
Missões, Parque Cangulo, carecem de infraestrutura básica de saúde, segurança e educação.Duque de Caxias não é apenas um local de moradia da classe trabalhadora, mas de existência de indústrias, atraídas desde pelo preço do solo até a flexibilidade de fiscalização. A busca por uma nova perspectiva socioeconômica deve estar atrelada com os aspectos ambientais, assim como de se lugar contra o sectarismo de seus habitantes e o coronelismo dos governantes desta cidade. A realidade de Duque de Caxias só mudará mediante a participação da população, tornando o município mais igual e justo em seus quatro distritos.

\section{NOTAS}

1. Consultar, neste mesmo periódico, o artigo de Fernando Ribeiro Camaz, intitulado "Duque de Caxias-Rio de Janeiro: contradições entre crescimento econômico e desenvolvimento social", que também trata das contradições desta cidade "rica economicamente" e "pobre socialmente". Disponível em: http://espacoeconomia.revues.org/2061.

2. Instalado em uma área de manguezal e próximo a Baía de Guanabara, este aterro ocasionou a remoção do saibro e a poluição do solo com Hexaclorociclohexano ( $\mathrm{HCH})$, popularmente conhecido como pó-de-broca, no bairro conhecido como Cidade dos Meninos.

\section{AUTOR}

\section{ANDRÉ LUIZ TEODORO RODRIGUES}

Aluno da Graduação em Geografia da UFRRJ - Universidade Federal Rural

do Rio de Janeiro e estudante do Grupo de Pesquisa Reestruturação Econômico-Espacial Contemporânea, vinculado ao LAGEPPE - Laboratório de Geografia Econômica e Política e Práticas Educativas. Bolsista do PIBID [Programa Institucional de Bolsa de Iniciação à Docência] - Geografia - UFRRJ, campus-sede. 